\title{
Interlingual Homophone Retrieval in Typical Malayalam - Hindi Bilinguals
}

\author{
Ferly Felix ${ }^{1}$, Satish Kumaraswamy ${ }^{2, *}$ \\ ${ }^{1}$ Department of Speech Language Pathology, Mangalore University, Karnataka, India \\ ${ }^{2}$ College of Speech and Hearing, Mangalore University, Karnataka, India
}

Email address:

ferlyfelix6@gmail.com (F. Felix),drmvcosh@gmail.com (S. Kumaraswamy)

${ }^{*}$ Corresponding author

\section{To cite this article:}

Ferly Felix, Satish Kumaraswamy. Interlingual Homophone Retrieval in Typical Malayalam - Hindi Bilinguals. Arabic Language, Literature \& Culture. Vol. 9, No. 1, 2021, pp. 12-19. doi: 10.11648/j.allc.20210601.12

Received: April 23, 2019; Accepted: January 8, 2020; Published: January 15, 2021

\begin{abstract}
Inter-lingual homophones are words that have similar pronunciation but different meanings across languages. The processing of this may vary with languages. Few studies in Indian languages have been attempted (Maitreyee and Goswami in Kannada-Hindi, Rajalekshmi, Kumaraswamy and Rao Hindi-English, Vinodhini and Ramya Tamil-English) in accordance with this. The aim of the present study was to investigate the language of dominance and its pattern in Malayalam -Hindi bilinguals using interlingual homophones. Twenty native speakers of Malayalam and 20 non- native Malayalam speakers participated who were graduate students. A non-standardized list of 20 paired- words was formed as a stimuli. Words belonging to both the languages (Malayalam and Hindi), having the pronunciation but different meaning were selected for the study. The findings of the present study suggested that one can perform better in first language (L1) without the interference of the other (L2) effectively, giving the picture oftwo separate lexicons for both the languages. They show a selective lexical-access (i.e., only one language is stimulated at a time) and this is in accordance with the earlier findings.
\end{abstract}

Keywords: Inter-lingual Homophone, Retrieval, Bilinguals

\section{Introduction}

Semantics is the study of meaning of words, phrases and sentences. The semantic analysis focuses on what the words conventionally mean, rather than on what a speaker might want the words to mean. Whereas in Linguistic Semantics it is the conventional meaning being conveyed by the word and sentences of a language. [7]

Homophones, Homonymy and polysemy describes the relationship among words in language. Homophones are two different words which are pronounced the same way but differ in meaning or spelling or both [29]. In other words, homophones are words that share the same sound but have different spellings and meanings [26].

Interlingual homographs share spelling but not meaning across languages. Therefore, each interlingual homograph has one orthographic representation whereas interlingual homophones have two orthographic representations, one for each language. Bilingualism is a unique experience to every individual with variability in the amount and quality of exposure to the languages the individual learns, as well as the experiences he or she has using the languages when interacting with others (American Speech and Hearing Association (ASHA), 2004). The processing of interlingual homophones may vary within languages and bilinguals have more difficulty in processing mixed sequences of words than sentences presented only in a single language.

The effect of interlingual homophones in VietnameseEnglish. Bilinguals prove that for each interlingual homophone, these unbalanced bilinguals were expected to have a phonological representation for both languages but an orthographic representation for first language alone. [23]

The inter-lingual homophone retrieval abilities in HindiKannada bilinguals which says that the native language will be more dominant for retrieval of the meanings of the words. [21]

the abilities of the meanings of the inter-lingual homophones is superior in their native languages (L1) in younger adults. And also those who learn different languages 
other than L1 exhibits equal proficiency in L1 and L2. [27]

one can perform better in first language (L1) without the interference of the other (L2) effectively, giving the picture of two separate lexicons for both the languages. [23] Individuals ability to have a reasonable command of two languages lexical items are subconsciously activated in both the languages and those in the language not required being suppressed [11].

Mercier, Pivneva and Titone (2013) reported that effective inhibitory control appears to help bilinguals overcome crosslanguage activation during spoken word comprehension. Moreover Pryle and Bogusch (2000-2001) argues that regular homophone practice enhances vocabulary knowledge, spelling skills, pronunciation ability, and overall reading proficiency.

Influence of the mother tongue and the pervasiveness of interlingual transfer is indisputable especially in learning situations where students exposure to the foreign language is confined to a few hours per week of formal classroom instruction (Mahmoud, 2000). Thus interlingual transfer is a strategy that isreadily available to the learners to compensate for the inadequacies when attempting to communicate in the foreign language.

Inter-lingual homophones are words that have similar pronunciation but different meanings across languages. The processing of this may vary with languages. Few studies in Indian languages have been attempted (Maitreyee \& Goswami, Rajalekshmi, Kumaraswamy and Rao, Vinodhini and Ramya) in accordance with this. Malayalam which is a Dravidian language used by $96.7 \%$ of people around the state of Kerala and they are exposed to learn other languages. [27, $23,20]$ The usage of only a single language at a time by a bilingual indicates the separation of the respective lexicons. In spite of the above fact an interlingual homograph activates target words in both of the bilingual's language in lexicaldecision tasks. Hence, there was a need to study the retrieval of semantics of the perceived inter-lingual homophones in Malayalam- Hindi Bilinguals.

\section{REVIEW OF LITERATURE}

Language impacts the daily living of members of any race, creed, and region of the world. Language helps express our feelings, desires, and queries to the world around us. Words are stored together in our brains by their relationships to each other. These interconnections have given rise to the concept of a language web. Language change happens at all levels from the phonological level to the levels of vocabulary, morphology, syntax and discourse.

Semantic is the study of meaning assumes in a relation between signs and meanings that are firmly established through social convention. The meaning of words is represented in terms of distributed semantic features. Inlinguistics; first language acquisition is closely related to the concept of a "native speaker".

Homophones are pairs of words that sound the same, but have distinctly different meanings and different spellings. Homophones are useful when studying phonology because they can differentiate whether the phonological or direct route to meaning is being used. In monolinguals, phonology plays a considerable role in visual word recognition [6].

Bilingualism is a fluctuating system in children and adults whereby use of and proficiency in two languages may change depending on the opportunities to use the languages and exposure to other users of the languages.

Interlingual homophones are terms that sound the same or very similar but do not have the same meaning in both languages.

Malayalam which is a Dravidian language used by $96.7 \%$ of people around the state of Kerala and they are exposed to learn other languages. Hindi is an Indon-Aryan language and, with all its dialects taken together, is the third most-widely spoken language in the world. The homeland of Hindi is in the North Of India, but it is studied, taught, spoken and understood widely throughout the sub-continent, whether as mother tongue or as a second or a third language

The usage of only a single language at a time by a bilingual indicates the separation of the respective lexicons. the false cognates involves representations in separate lexicons [2,5]. The interpretation of false cognates was constrained by meaning rather than language and the results imply that lexical representation in bilinguals is organized along morphological lines and is not governed by language when processing an interlingual homograph. [16, 86]

There are a number of models which explains the phenomenon of visual orthographic processing in bilingual individuals and have studied on bilingual lexical representation.

Kroll and Stewart (1994) proposed the revised hierarchical model (Figure 1.) to capture the implications of early reliance on L1 for the form of word-to-concept connections. [15]

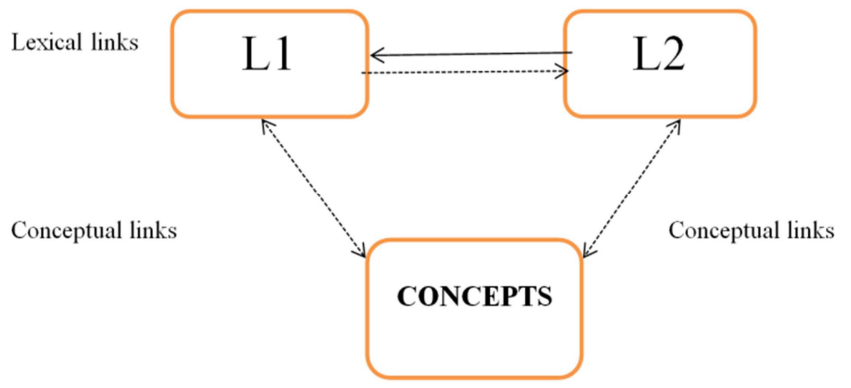

Figure 1. Ref: Revised Hierarchical Model (source: Adapted from Kroll \& Stewart, 1994).

The model fuses the word association and concept mediation alternatives into a single model in which the strength of the connections between words in L1 and L2 and concepts is proposed to take on different values. The initial dependence on L1 to mediate access to meaning for L2 words is assumed to create strong lexical level connections from L2 to L1. However, at a lexical level, the connections from L1 to L2 are not assumed to be particularly strong because there is a little need for the learner to use L2 in this way. Likewise, the model assumes that connections between words and concepts are stronger for L1 than for L2. A number of empirical findings supports the predictions of the 
revised hierarchical model. More critically, only translation from L1 to L2 was influenced by the presence of semantic information. The absence of semantic effects in the L2 to L1 direction of translation suggests that it was possible for bilinguals to translate directly at a lexical level.

All the models proposed till date have mostly examined the representation of both the languages in a bilinguals brain using homographs, cognates, etc and hence have evaluated the visual orthographic processing in them. Research in alphabetic languages (English, Dutch) has frequently indicated a non - selective lexical access of the orthographic mental lexicon in bilinguals.

\section{WESTERN STUDIES}

the most individuals loose or recover multiple languages equally, but some recover one before the other, and some recover either L1 or L2. These outcomes insist that two or more languages may have different representation or levels of activation. [24]

Content plays a role in accessing words in one language or another, and those bilinguals have more difficulty in processing mixed sequences of words than sentences presented only in a single language. [9] This finding reflects that the opening word of the sentence 'switches on' the lexicon in either of the bilinguals languages and that all lexical searching takes place initially in that particular lexicon.

The recognition of spoken homophones is a result of the interactions among phonological, lexical, and contextual information in both monolinguals and bilinguals. [26] Bilinguals access the meaning in both their languages when taking vocabulary tests in one of their languages.

Cross-language homophones in the lexical processing of Chinese-English bilinguals. [16] The results of their crossmodal naming show that the predictive sentence context significantly facilitates Chinese-English bilinguals' recognition of homophones, which in turn facilitates their naming of the phonologically related words. Similarly, in a recent eye-tracking study using English-French homophones (e.g. pool - poule).

Jared and Levy, B. A. and Rayner, K (1999) examined the role of phonology in the activation of word meanings and found that phonology plays a role in activating the meanings of low-frequency words when correct homophones were not predictable and the impact of reading skill was examined. Overall the study demonstrated the role of phonology in the activation of word meanings and pseudo homophony in a lexical decision task the evidence indicated that phonology plays a role in activating. homophone effects for words in isolation using a lexical decision task (LDT) and suggested that phonology plays a role early in the word-recognition process Homophones were found to have longer decision latencies than matched control words in the LDT. [12]

Chambers and Crooke (2009) demonstrated that a semantically compatible sentence context eliminates the activation of the English lexicon when interpreting French sentences. Once again, these studies provide evidence that the degree of non-selective activation is influenced by the semantic characteristics of the sentence context. [4],[12] Hino and colleagues researched inconsistent with studies of both English and Chinese homophones were inhibitory homophone effects were found for homophones with few homophonic matewhereas facilitative homophone effects were found for homophones with many homophonic mates. These results suggest that homophone density may explain the discrepancy in results found in studies of English and Chinese homophones. Hino and colleagues explain the facilitative effect of increased homophone density using the global activation account. The authors suggest that when a word has many homophonic mates, the increased global activation in the lexicon facilitates one's ability to decide on the homophone's status as a word. One homophonic mate is not enough to cause this increased global activation.

The performance of native and non-native English speakers with similar age and educational backgrounds on a variety of cognitive tests. [14] The results suggest that nonnative English language may have a negative influence predominantly on language-dependent tasks.

\section{INDIAN STUDIES}

The inter-lingual homophone retrieval abilities in HindiKannada bilinguals. [20] The results revealed that the native language was more dominant for retrieval of the meanings of the words for children and adults in both Kannada and Hindi native speakers. On the other hand teenagers performed similarly in both the languages. It is hypothesized that a bilingual has separate lexicons for L1 and L2 in the younger age, and then an interaction occurs between both the lexicons and finally the most used language becomes dominant.

The two later-acquired but proficient languages, English and Hindi, of two multilingual individuals with transcortical aphasia basal ganglia lesion in GN and brain stem lesion in GS). [30] Dissociation between lexical and syntactic profiles in both the languages with a uniform performance across the languages at the lexical level and an uneven performance across the languages at the syntactic level were observed

The language of dominance and its pattern in HindiEnglish bilinguals and multi-lingual's using inter-lingual homophones. [27] Data was collected from 40 participants who were bilinguals. Twenty paired-words which consisted of inter-lingual homophones were used as stimulus. Result shows that the retrieval of the meanings of the inter-lingual homophones is superior in their native languages (L1) in younger adults. Those who learn different languages other than L1 exhibits equal proficiency in L1 and L2.

The language of dominance and its pattern in TamilEnglish bilinguals and multi-lingual's using inter-lingual homophones. [23] Data were collected from total of 60 participants (9-45 yrs) who are bilinguals (native speakers of Tamil and have acquired English as their second language). The participants were sub grouped into: Group I= 9-18 yrs; $\mathrm{II}=19-28 \mathrm{yrs}$; and $\mathrm{III}=29-45 \mathrm{yrs}$. Twenty paired words which consisted of inter-lingual homophones were presented. The participants were asked to listen carefully to the pairs of words which were in two different languages that they knew 
and were asked to write the meaning of each word. The study reveals that native language (L1) was more dominant for retrieval of the meanings of the words for group II and III. Hence results suggest that younger subjects of group I exhibit a shared lexicon and Subjects of group II and group III show a selective lexical-access.

This is an indicative of the fact that L1 has a stronger base compared to L2 while processing inter-lingual homophones.

\section{Methodology}

\section{1. $A I M$}

The present study aims at investigating the inter-lingual homophone retrieval abilities in typical bilinguals and to investigate the language of dominance and its pattern in Malayalam-Hindi bilinguals using inter-lingual homophones.

\subsubsection{Participants}

Forty graduates (Twenty native of Malayalam and Twenty non-natives) in the age range of 18-23 who were proficient with Malayalam and Hindi language in their day today life participated in the present study. Participants with any form of Hearing, Neurological problems were excluded from the study.

\subsubsection{Stimulus Preparation}

A list of 20 paired words which were commonly used from both languages (Malayalam and Hindi) formed homophones. The prepared word list was then given to Speech Language Pathologists who were proficient with both languages and working in the field for more than 10 years for judging the appropriateness of words and validation.

The validated list was recorded by examiner with high quality condenser microphone.

\subsection{Procedure}

The validated pair of words list was displayed using headphone Sony Viao Laptop to the participants in a well illuminated room. The participant's task was to listen and see the presented word list carefully and was asked to write the meaning of each word.

\subsection{Analysis}

A score of 1 for correct writing with meaning and 0 for wrong writing was given and the obtained data was statistically analyzed using Descriptive statistics and results are discussed in next chapter.

\subsection{Need}

Inter-lingual homophones are words that have similar pronunciation but different meanings across languages. The processing of this may vary with languages. Few studies in Indian languages have been attempted (Maitreyee and Goswami (2009) in Kannada-Hindi, Rajalekshmi, Kumaraswamy and Rao (2015) Hindi-English, Vinodhini and Ramya Tamil-English (2015)) in accordance with this. Malayalam which is a Dravidian language used by $96.7 \%$ of people around the state of Kerala and they are exposed to learn other languages. The usage of only a single language at a time by a bilingual indicates the separation of the respective lexicons. In spite of the above fact an interlingual homograph activates target words in both of the bilingual's language in lexical-decision tasks. Hence, there was a need to study the retrieval of semantics of the perceived inter-lingual homophones in Malayalam- Hindi Bilinguals.

\section{Results \& Discussion}

The aim of the present study was to investigate the language of dominance and its pattern in Malayalam-Hindi bilinguals and multilingual using interlingual homophones.

The data were tabulated and analyzed using SPSS version 16. Descriptive statistics (mean and standard deviation values and ' $\mathrm{T}$ ' test) for both the groups of speakers for Malayalam and Hindi was used to analyze the information and the results are discussed below.

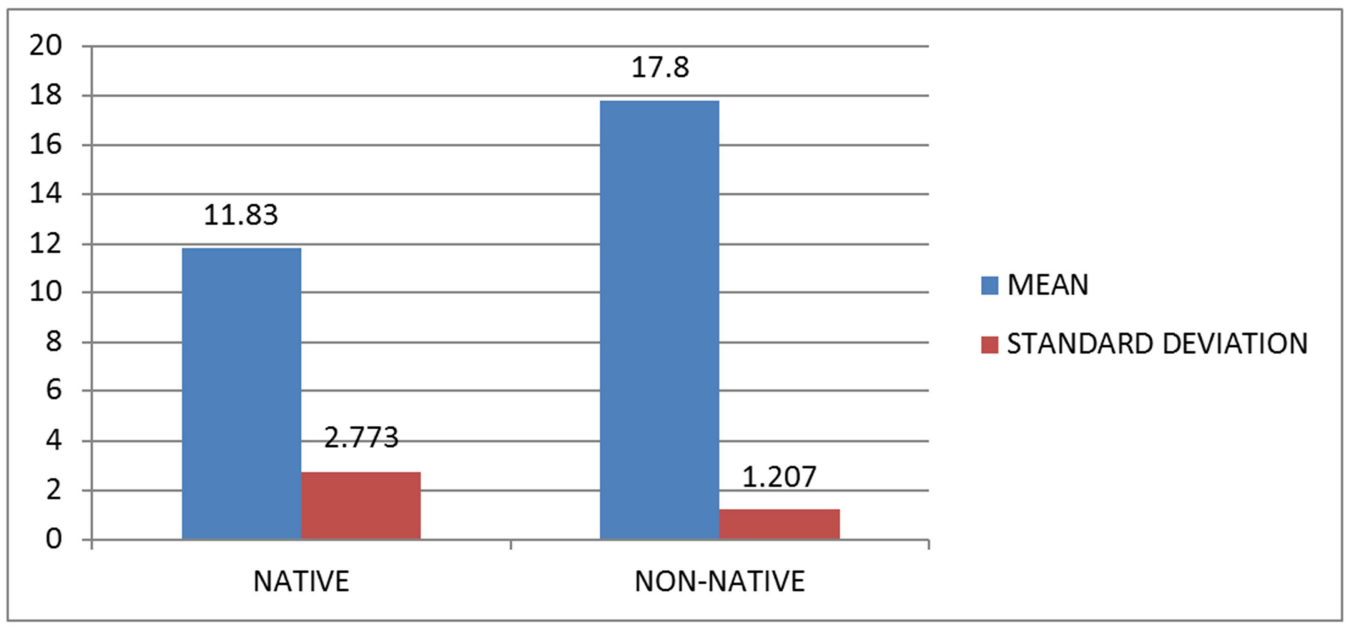

Figure 2. Showing the Mean \& Standard Deviation value for native and non-native Speakers for Hindi words. 
Table 1. Showing the Mean, Standard deviation and significant value for native and non-native speakers for Hindi words.

\begin{tabular}{|c|c|c|c|c|c|}
\hline Group & $\mathbf{N}$ & Mean & Std. Deviation & t value & $\mathbf{p}$ \\
\hline NATIVE SPEAKERS & 20 & 11.83 & 2.773 & 8.834 & .000 \\
\hline NON NATIVE SPEAKERS & 20 & 17.80 & 1.207 & & HS \\
\hline Total & 40 & 14.81 & 3.689 & & \\
\hline
\end{tabular}

From the above table and figure it can be seen that non-native speakers performed better compared to native speakers for Hindi words and statistically ---significant difference $(p=.00)$, which shows that non-native speakers had strong hold on the words.

Parameter: MALAYALM.

Table 2. Showing the Mean, Standard deviation and non-significance for native and non-native Speakers for Malayalam words.

\begin{tabular}{|c|c|c|c|c|c|}
\hline Group & $\mathbf{N}$ & Mean & Std. Deviation & t value & p \\
\hline NATIVE SPEAKERS & 20 & 20.00 & .000 & - & NS \\
\hline NON NATIVE SPEAKERS & 20 & 20.00 & .000 & & \\
\hline Total & 40 & 20.00 & .000 & & \\
\hline
\end{tabular}

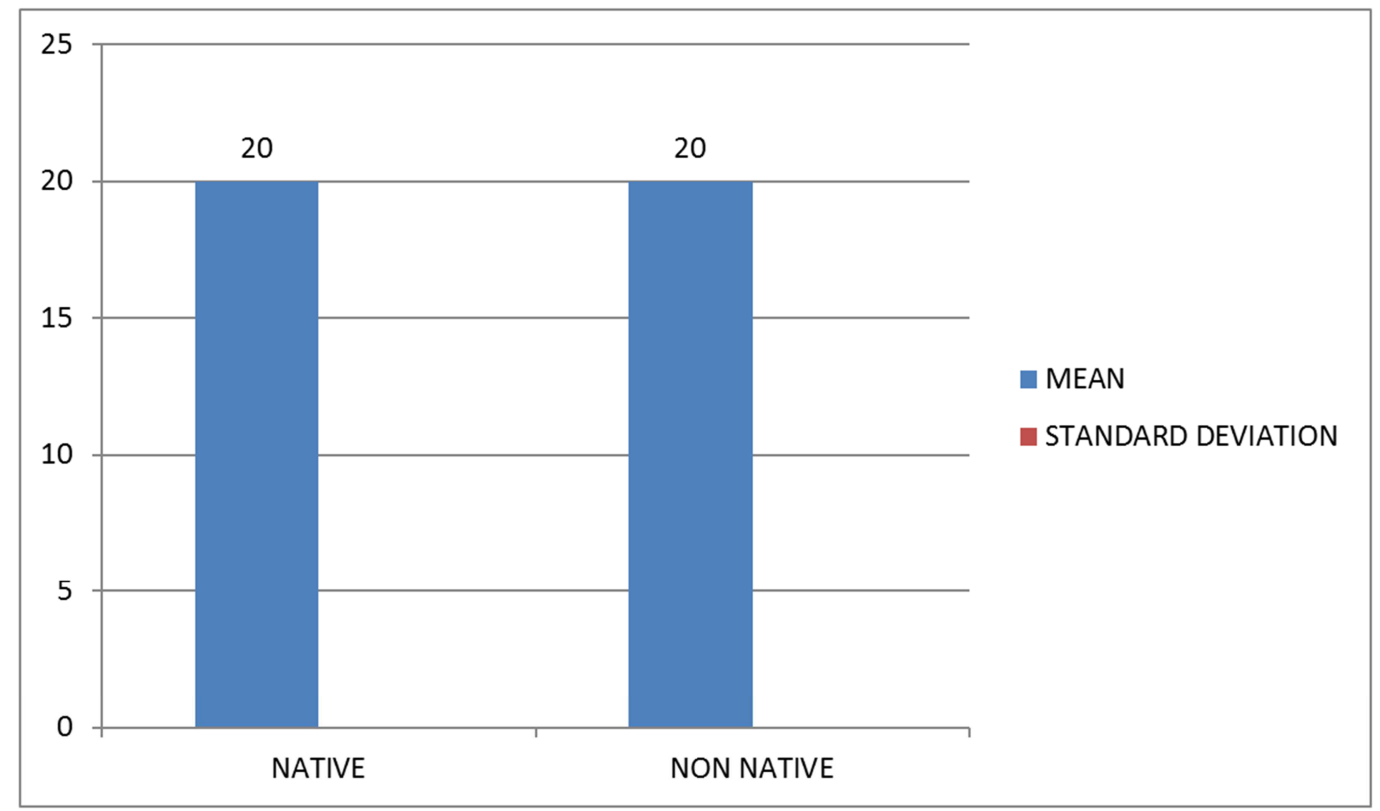

Figure 3. Showing the Mean \&standard deviation score for native and non-native Speakers for Malayalam words.

From the above table and figure it can be inferred that the native and non-native speakers performed equally well for Malayalam words and no significant difference was noticed for the same.

Table 3. Showing Mean, Standard deviation \& P value for words across speakers and words.

\begin{tabular}{llllll}
\hline Group Parameter & N & Mean & Standard Deviation & t value & p \\
\hline NATIVE HINDI & 20 & 11.83 & 2.773 & \multirow{2}{*}{13.18} & .000 \\
MALAYALM & 20 & 20.00 & .000 & & HS \\
NON HINDI & 20 & 17.80 & 1.207 & 8.15 & .000 \\
NATIVE MALAYALM & 20 & 20.00 & .000 & & HS \\
TOTAL HINDI & 40 & 14.81 & 3.689 & 8.89 & .000 \\
MALAYALM & 40 & 20.00 & .000 & HS \\
\hline
\end{tabular}

From the above table when the data was cross compared across native and non-native speakers for Malayalam and Hindi words high significant difference $(p=.00)$ was noticed.

The present study reveals that the retrieval of meanings of inter-lingual homophones are superior in native language i.e., L1 in younger adults. It also suggests that one performed better in native (L1) without the interference of other language (L2).
It can also be concluded that individuals have reasonable commands on two languages which are subconsciously activated in both the languages and those in the language not required being suppressed.

\section{Discussion}

Results indicated that non-native speakers perform better 
for Hindi words and significant difference $(\mathrm{P}=.00)$ was obtained whereas for Malayalam word both native and nonnative speakers perform equally well and no significant difference was seen.

Cross comparison of data for Hindi and Malayalam words for native and non-native speakers yielded high significant difference $(\mathrm{P}=.00)$ which reveals that the retrieval of meanings of inter-lingual homophones are superior in native language i.e. L1 in younger adults. The present findings are in accordance with Maitreyee \& Goswami (2009), Rajalekshmi \& Kumaraswamy (2015), Vinodhini \& Ramya (2015) where they say that native language will be more dominant for the retrieval of the meanings of words for children and adults. These results are also in accordance with the studies done earlier stating that the bilinguals organize and retrieve words mainly in their dominant language (Curtis, 1978). This difference of better retrieval abilities in the native language, i.e., L1 can also be well explained with the help of the Revised Hierarchical Model (Kroll \& Stewart, 1994). Based on this model it can be assumed that the word-concept association has stronger links when the word belongs to L1 than in L2. This is indicative of the fact that L1 has a stronger base compared to L2 while processing inter-lingual homophones.

The findings of the present study also suggested that one can perform better in first language (L1) without the interference of the other (L2) effectively, giving the picture of two separate lexicons for both the languages. They show a selective lexical-access (i.e., only one language is stimulated at a time) and this is in accordance with the earlier findings (Gerard \& Scarborough, 1989). This was in contradiction of present study in which it was stated that when a person has a reasonable command of both the languages, lexical items are subconsciously activated in both the languages (Green, 1986).

\section{Summary and Conclusion}

Inter-lingual homophones are words that have similar pronunciation but different meanings across languages. Each Inter-lingual homograph has one orthographic representation whereas inter-lingual homophones have two orthographic representations for each language.

Bilingualism is a unique experience to every individual with variability in the amount and quality of exposure to the languages the individual learns, as well as the experiences he or she has using the languages when interacting with others (American Speech and Hearing Association, 2004). The processing of inter-lingual homophones may vary with languages. Studies in Indian languages have been attempted (Maitreyee and Goswami (2009), Rajalekshmi, Kumaraswamy and (2015), Vinodhini and Ramya (2015) in accordance with this. Malayalam is a Dravidian language used by $96.7 \%$ of people around the state of Kerala and who are exposed to learn other languages.

Usage of only a single language at a time by a bilingual indicates the separation of the respective lexicons. In spite of the above fact an inter-lingual homograph activates target words in both of the bilingual's language in lexical-decision tasks. Hence, need arises to study the retrieval of semantics of the perceived inter-lingual homophones in Malayalam- Hindi Bilinguals. Hence the present study aims at investigating the inter-lingual homophone retrieval abilities in normal bilinguals and also to investigate the language of dominance and its pattern in Malayalam-Hindi bilinguals and multi-lingual's using inter-lingual homophones and to fulfill this aim 40 graduate students further divided into 20 native (Malayalam) 20 non-native (Hindi) speakers with no evident health problem or any associated illness participated in present study.

A list of 20 paired words (Malayalam and Hindi) was presented to all subjects whose task was to listen carefully the pair of words and to write the meaning of each word. The responses were then tabulated according to number of correctly written word with correct meaning in each language by giving the score of 1 for the wrong written word with incorrect meaning by giving 0 and further the data was analyzed.

Results indicated that non-native speakers perform better for Hindi words and significant difference $(\mathrm{P}=.00)$ was obtained whereas for Malayalam word both native and nonnative speakers perform equally good and no significant difference $(\mathrm{P}=.00)$ was seen.

Cross comparison of data for Hindi and Malayalam words for native and non-native speakers yielded high significant difference $(\mathrm{P}=.00)$ which reveals that the retrieval of meanings of inter-lingual homophones are superior in native language i.e. L1 in younger adults. From the above results it can be summarize that individuals have reasonable commands on two languages which are subconsciously activated in both the languages and those in the language not required being suppressed.

\subsection{Implication of the Study}

The study has its implications in the assessment, diagnosis and the intervention planning programs for bilingual younger adults. The retrieval of semantics of the perceived inter-lingual homophones which help us to know the influence of homophone words on language perception and processing. For adults, L1 can be considered as a medium of instruction during remediation, which will help to select the appropriate language of intervention for bilingual aphasic clients.

\subsection{Limitation of the Study}

a. Subject selected were limited in number in each group.

b. Excluded Malayalam-Hindi bilingual children's and older adults.

c. A large sample would have yielded more reliable results.

\subsection{Future Directions}

a. The present study could be further extended in a larger population.

b. The study could be conducted with children and teenagers. 


\section{Appendix}

Table 4. Phonetic Transcription for Stimulus Materials.

\begin{tabular}{|c|c|}
\hline Interlingual Homophones & Phonetic Transcription \\
\hline Kalam & $/ \mathrm{k}$ a 1 a $\mathrm{m} /$ \\
\hline Chumma & $/ \mathrm{t} \int \mathrm{uma} /$ \\
\hline Morre & $/ \mathrm{m}$ o r ae/ \\
\hline Chorr & $/ \mathrm{t} \int \mathrm{or} /$ \\
\hline Payal & / p a y a $1 /$ \\
\hline Sooji & / su : fI / \\
\hline Chaya & $/ \mathrm{t} \int \mathrm{aja} /$ \\
\hline Theri & /e : tri \\
\hline Chaar & $/ \mathrm{t} \int \mathrm{ar} /$ \\
\hline Thamasha & / tm a sh a/ \\
\hline Mook & $/ \mathrm{mu}: \mathrm{k} /$ \\
\hline Kalle & $/ \mathrm{k}$ a $1 \mathrm{e} /$ \\
\hline Maan & $/ \mathrm{m}$ a a $\mathrm{n} /$ \\
\hline Palle & $/ \mathrm{p}$ a 1 lis/ \\
\hline Pathi & /p a țI/ \\
\hline Paaya & $/ \mathrm{p}$ a a y a/ \\
\hline Kaka & $/ \mathrm{k} \mathrm{a} \mathrm{k} \mathrm{a/}$ \\
\hline Koyyi & / ko: : V \\
\hline Aana & $/ a: n /$ \\
\hline Prathi & $/ \mathrm{p} \mathrm{rttI}$ \\
\hline
\end{tabular}

\section{References}

[1] Beauvillian, C. \& Grainger, J. (1987). Accessing interlexical homographs: Some limitations of a language selective access. Journal of Memory and Language, 26, 658-672.

[2] Bybee, J. L. (1985). Morphology: A study of the relation between meaning and form. Amsterdam: John Benjamins.

[3] Chambers CG, Cooke H (2009) Lexical competition during second-language listening: sentence context, but not proficiency, constrains interference from the native lexicon. J ExpPsychol Learn MemCogn. 2009 Jul; 35 (4): 1029-40. doi: 10.1037/a001590.

[4] Hino, Y., Kusunose, Y., Lupker, S. J., \& Jared, D. (2013). The processing advantage anddisadvantage for homophones in lexical decision tasks. Journal of Experimental Psychology: Learning, Memory, and Cognition, 39 (2), 529-551.

[5] Costa, A. \& Carmazza, A. (1999). Is lexical selection in bilinguals language-specific? Further evidence from SpanishEnglish \& English-Spanish bilinguals. Bilingualism, Language \& Cognition, 2, 231-244.

[6] Frost, R. (1998). Toward a strong phonological theory of visual word recognition: True issues and false trails. Psychological Bulletin, 123, 71-99.

[7] George Yule. (2010). The study of language, $4^{\text {th }}$ edition.

[8] Gerard, L., \& Scarborough, D. (1989). Language specific lexical access of homographs by bilinguals. Journal of Experimental Psychology: Learning, Memory and Cognition, 15, 305-313.

[9] Grainger, J. (1994). Le lexiquebilingue: approchesde la psychologie experimentale. Revue de Phonetique Appliquee, 112/113, 221-238.

[10] Green, D. (1986). Control, activation and resource: a framework and a model for the control speech in bilinguals. Brain and Language, 27, 210-223. J Exp Psychol Learn Mem
Cogn. Jan; 27 (1): 139-56.

[11] Green, D. W. (2003). The neural basis of the lexicon and the grammar in L2 acquisition.

[12] In R. Van Hout, A. Hulk, F. Kuiken \& R. Towell (eds.), The interface between syntax and the lexicon in second language acquisition, pp. 197-218. Amsterdam: John Benjamins.

[13] Jared, D., Levy, B. A., \&Rayner, K. (1999). The role of phonology in the activation of word meanings during reading: Evidence from proofreading and eye movements. Journal of Experimental Psychology: General, 128 (3), 219-264.

[14] Kisner. K (1986) Lexical representation: Is a bilingual account necessary? In J. vaid (Ed). Language processing in bilinguals Psycholinguistic and neuropsychological perspectives Hillsdale, NJ: Erlbaum.

[15] Kisser JE, Wendell CR, Spencer RJ, Waldstein SR. (2012). Neuropsychological performance of native versus non-native English speakers.

[16] Kroll, J. F., \& Stewart, E. (1994). Category Interference in Translation and Picture Naming- Evidence for Asymmetric Connections Between Bilingual Memory Presentations. Journal of Memory and Language, 33, 149-174.

[17] Lalor, E. \& Kirsner, K. (2001). The representation of the "false cognates" in the bilingual lexicon. Psychonomic Bulletin \& Review, 8, 552-559.

[18] Ping Li \&MichaelC. Yip (1998) Context effects and the processing of spokenhomophones. Cognitive Processing of the Chinese and the Japanese Languages pp 69-89.

[19] Mahmoud, A. (2000) Modern standard Arabic vs Nonstandard Arabic: Where do Arab students transfer from? Language, Culture and Curriculum, 13, 126-136.

[20] Marilyn Bogusch Pryle (200-2001). Peek, Peak, Pique: Using Homophones to Teach Vocabulary (and Spelling!).

[21] Maitreyee, R., \& Goswami, S. P. (2009) Interlingual Homophone Retieval in Bilinguals. Journal of Indian SpeechLanguage and Hearing Association, 23, 33-41.

[22] Mercier, Pivneva, \&Titone, (2013) Individual Differences in Inhibitory Control Relate to Bilingual Spoken Word Processing (Bilingualism: Language and Cognition).

[23] Nguyen, N. (2014). The Effect of Interlingual Homophones in Vietnamese-English Bilinguals. Western Undergraduate Psychology Journal, 1 (1).

[24] Palaniappan Vinodhini, Senthilkumar Ramya, Rajan, N. D., M Sc. Speech and Hearing (September 2015). Retrieval of InterLingual Homophones among Tamil Native Bilinguals. Language in India www.languageinindia.com ISSN 1930294015: 9 .

[25] Paradis, M. (1987). The assessment of bilingual aphasia. Hillsdale, NJ: Lawrence Erlbaum.

[26] Pexman PM, Lupker SJ, Jared D (2001) Homophone effects in lexical decisions.

[27] Rajalekshmi. S., Satish. K. \& Dr. T. A. Subba Rao (March 2015). Inter-lingual Homophone Retrieval in Younger Adults, Language in India www.languageinindia.com ISSN 19302940 15: 3 . 
[28] Riggs, F. W. (2005) A semantic/ OnomanticPuzzele on Homonyms, Heteronyms and Allonyms' In Homonymy.

[29] Stephen J. Lupker and Debra Jared (2013). The Processing Advantage and Disadvantage for Homophones in Lexical Decision Tasks Yasushi Hino and Yuu Kusunose Waseda University Stephen J. L, Journal of Experimental Psychology:
(C) 2012 American Psychological Association Learning, Memory, and Cognition,, Vol. 39, No. 2, 529-55.

[30] Venkatesh, M., Edwards, S., \& Saddy, J. (2012) Production and comprehension of English and Hindi in multilingual transcortical aphasia. Journal of Neurolinguistics, 25, 615629. 